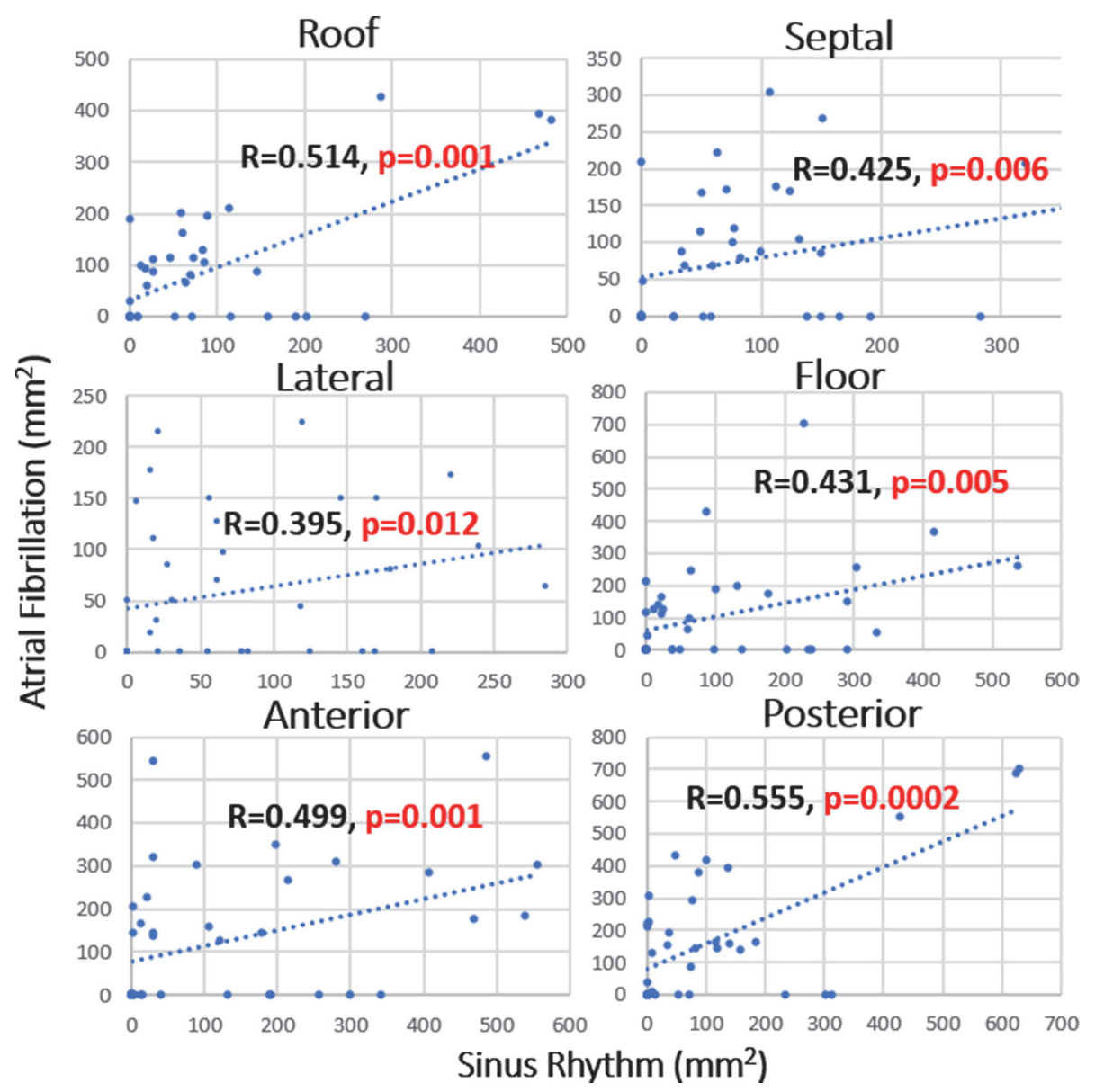

Abstract 10 Figure 2 Correlation scatterplot of LVAs $\leq 0.2 \mathrm{mV}$

Figure 2: Correlation coefficients of anatomical segment at voltages consistent with dense scar $\leq 0.2 \mathrm{mV}$ (in mm ${ }^{2}$ of endocardium fitting that voltage category) between rhythms of SR and AF.

significance in the Posterior $\left(\mathrm{AF}=234 \mathrm{~mm}^{2} \pm 150.45\right.$; SR $\left.=138.27 \mathrm{~mm}^{2} \pm 112.3, \mathrm{p}=<0.001\right)$, Roof $(\mathrm{AF}=150.61$ $\left.\mathrm{mm}^{2} \pm 93.17 ; \mathrm{SR}=115 \mathrm{~mm}^{2} \pm 77.14, \mathrm{p}=0.01\right)$, Anterior $\left(\mathrm{AF}=220.87 \mathrm{~mm}^{2} \pm 173.07 ; \mathrm{SR}=158.53 \mathrm{~mm}^{2} \pm 99.22\right.$ $\mathrm{p}=0.002)$ and Lateral AS $\left(\mathrm{AF}=137.05 \mathrm{~mm}^{2} \pm 104.99\right.$; $\left.\mathrm{SR}=87.52 \mathrm{~mm}^{2} \pm 66.82, \mathrm{p}=<0.001\right)$ as seen in table 1 . The voltage range of $0.21-0.5 \mathrm{mV}$ demonstrated weak correlation coefficients of $\mathrm{R}=0.09-0.31$, only reaching significance on the Posterior AS, once again shown in table 1.

Conclusions LVA burden $0.21-0.5 \mathrm{mV}$ in AF is significantly higher in SR with poor correlation, suggesting a greater influence of rhythm in this range and so care must be taken in interpretation. Comparatively, at dense scar voltages $(\leq 0.2$ $\mathrm{mV}$ ), we found comparable burden with good correlation between $\mathrm{AF}$ and SR, reflecting true readings in both rhythms. These findings should be carefully considered by operators performing additional scar modification and ablation.

\section{CLINICAL ASSOCIATIONS AND PATHOLOGICAL MECHANISMS OF REDUCED ATRIAL CONDUCTION VELOCITY}

D O'Hare, L O'Neill, I Sim, I Kotadia, R Bendikas, C Roney, S Niederer, JA Solis Lemus, O Razhegi, SE Williams, M O'Neill. King's College London, UK

10.1136/heartjn--2021-ICS.11
Conflict of Interest Dr. O'Hare has been the recipient of educational grants from Daiichi Sankyo and Johnson and Johnson Medical Ltd. during the course of this study.

Background The complex pathogenesis of atrial fibrillation (AF) remains unclear. A key concept is that for AF to be sustained, both a trigger and an atrial substrate capable of perpetuating the arrhythmia are required. Pathological remodelling in the atria can be observed after only a few minutes of high atrial rate, with the chronicity of these changes being directly related to the duration of the episodes of high atrial rate. This underpins the often-quoted axiom 'AF begets $\mathrm{AF}$ '. Increased atrial fibrosis in patients with $\mathrm{AF}$ has been observed in both histological and non-invasive studies using LGE-CMR atrial imaging. Reduced atrial conduction velocity $(\mathrm{CV})$ has been observed in fibrotic areas, which may propagate $\mathrm{AF}$ as more wavefronts can be sustained in the atria. It is unclear if reduced atrial $\mathrm{CV}$ is a prerequisite for $\mathrm{AF}$, or if it develops after the initial periods of arrhythmia. The use of 3D electro-anatomical mapping (EAM) has led to advancement in the accuracy of intra-cardiac CV measurement and investigations into the mechanism for reduced CV.

Hypothesis We hypothesised that left atrial CV plays a key role in the AF disease process and investigation into atrial $\mathrm{CV}$ may improve understanding into the pathogenesis and clinical course of AF. METHODS A systematic review was performed to assess current published evidence. This informed the design of a retrospective study to calculate $\mathrm{CV}$ from the left atrial 
local activation time (LAT) electro-anatomical maps of 90 paroxysmal AF (PAF) and 90 persistent AF (PsAF) patients presenting for first time PVI. Following this, pathological mechanisms were assessed by looking at the associations between left atrial CV determined from EAMs and 3D atrial LGE-CMR in 96 patients. Finally, a pilot study was designed and undertaken to investigate if atrial CV at rest, and at varying heart rates with exercise can be measured non-invasively with the use of electrocardiographic imaging (ECGI) and CMR.

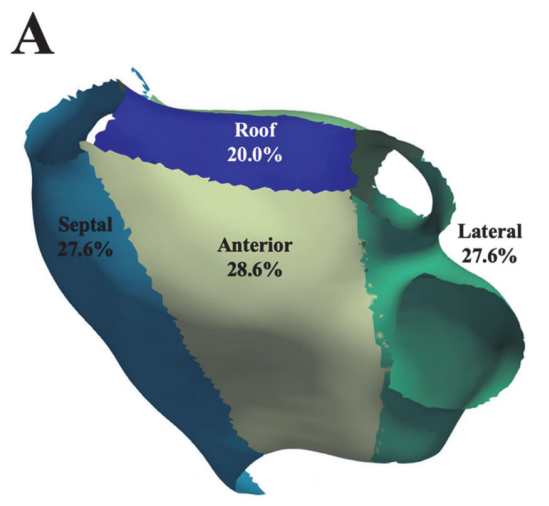

Results There was no statistical difference in the left atrial CV of patients with PAF compared to PsAF $(0.68 \mathrm{~m} / \mathrm{s}$ vs $0.69 \mathrm{~m} / \mathrm{s}$ respectively, $\mathrm{p}$-value $=0.70)$. Left atrial $\mathrm{CV}$ did not predict recurrence of AF in the first year after PVI. (Figure 1) Regional analysis of 3D atrial LGE-CMR in 96 patients, found significant variation in the distribution of fibrosis, however fibrosis burden was not significantly correlated with either overall or regional CV. (Figure 2). A pilot study using ECGI with CMR imaging was able to non-invasively measure bi-atrial CV during rest and three exercise stages. CV restitution properties

\begin{tabular}{|l|c|c|c|}
\hline & $\begin{array}{c}\text { Fibrosis burden } \\
\text { (\% of total area) }\end{array}$ & $\begin{array}{c}\text { Conduction } \\
\text { Velocity }(\mathbf{m} / \mathbf{s})\end{array}$ & $\begin{array}{c}\text { Correlation } \\
\text { P-Value }\end{array}$ \\
\hline Anterior & $\mathbf{2 8 . 6} \pm 23.5$ & $\mathbf{0 . 7 3 1} \pm 0.18$ & 0.57 \\
\hline Lateral & $\mathbf{2 7 . 6} \pm 22.0$ & $\mathbf{0 . 7 8 6} \pm 0.18$ & 0.34 \\
\hline Posterior & $\mathbf{3 5 . 6} \pm 24.6$ & $\mathbf{0 . 7 3 5} \pm 0.16$ & 0.42 \\
\hline Septal & $\mathbf{2 7 . 6} \pm 21.8$ & $\mathbf{0 . 7 9 3} \pm 0.18$ & 0.87 \\
\hline Roof & $\mathbf{2 0 . 0} \pm 21.2$ & $\mathbf{0 . 8 3 2} \pm 0.25$ & 0.35 \\
\hline
\end{tabular}

Abstract 11 Figure 1 AF recurrence survival analysis

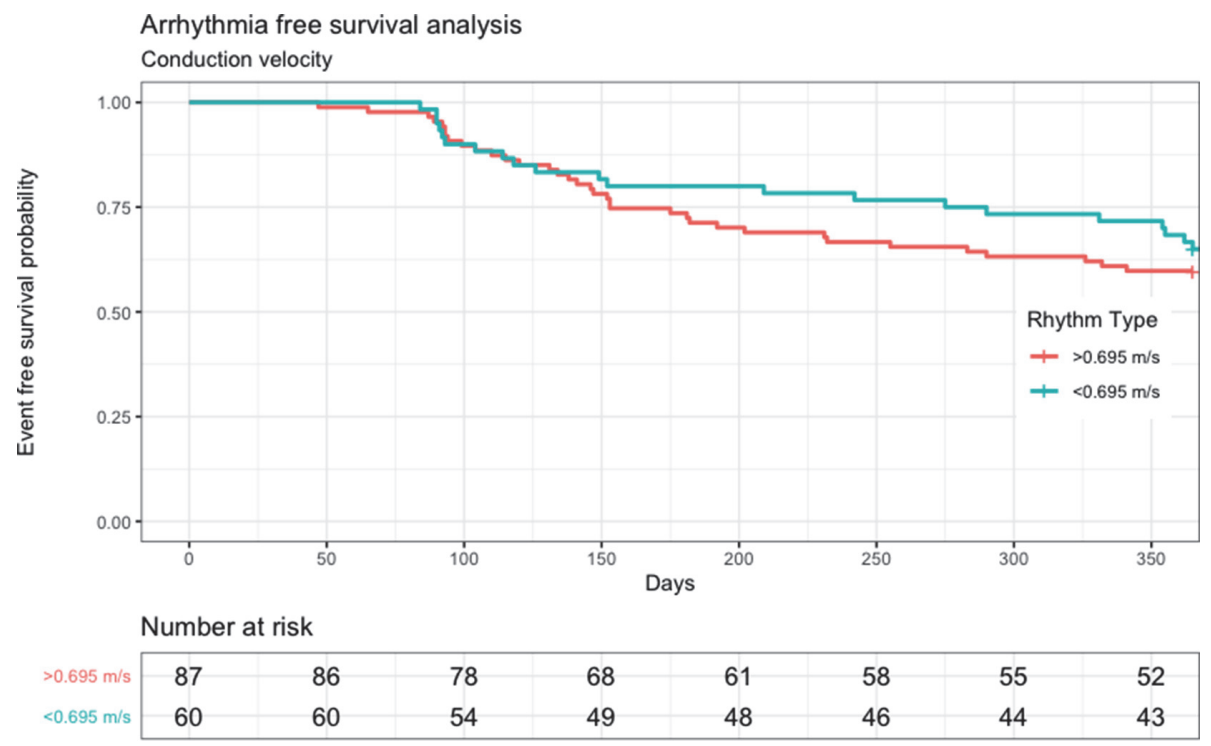

Abstract 11 Figure 2 Regional variation in left atrial scar and correlation with CV $(A=$ Anterior $L A$ view, $B=$ Posterior $L A$ view) 
were not demonstrated in this healthy cohort in heart rates up to $150 \mathrm{bpm}$.

Conclusions Reduced atrial $\mathrm{CV}$ is a common finding in $\mathrm{AF}$, however $\mathrm{CV}$ is similar in patients with PAF and PsAF in sinus rhythm during PVI. Alterations in CV did not correspond to fibrosis detected on atrial LGE-CMR, suggesting that pathological changes other than fibrotic remodelling account for the reduction in $\mathrm{CV}$ seen in these patients.

\section{COMPARISON OF SLOW VS. RAPID AJMALINE INFUSION PROTOCOL FOR THE DIAGNOSIS OF BRUGADA SYNDROME (BRS): TEN YEAR EXPERIENCE OF THE NORTHERN IRELAND INHERITED CARDIAC CONDITIONS SERVICE (NI ICC)}

${ }^{1,2} \mathrm{HM}$ Sulaiman, ${ }^{1} \mathrm{P}$ Brennan, ${ }^{1} \mathrm{H}$ Connolly, ${ }^{1} \mathrm{~J}$ McOsker, ${ }^{1} \mathrm{~T}$ Jardine, ${ }^{1} \mathrm{~A}$ Miur. ${ }^{1}$ Belfast Health and Social Care Trust, UK; ${ }^{2}$ Cormac Fellowship, UK

10.1136/heartjnl-2021-ICS.12

Introduction $\mathrm{BrS}$ is diagnosed in patients with ST-segment elevation with type 1 morphology $\geq 2 \mathrm{~mm}$ in one or more leads among the right precordial leads $\mathrm{V} 1$ and/or V2 positioned in the second, third or fourth intercostal space. This may be spontaneous or after provocation challenge with intravenous administration of a sodium channel blocker (i.e. ajmaline, flecainide, procainamide or pilsicainide). The specific protocol for ajmaline provocation challenge for diagnosis of $\mathrm{BrS}$ has been debated between ICC services worldwide. Concerns regarding safety and false positive rates are perceived to be associated with a more rapid infusion protocol. This retrospective observational cohort study describes the safety and positivity rates for patients undergoing ajmaline provocation challenge by both protocols over ten years.

Methods Data on consecutive adults undergoing ajmaline challenge test from Mach 2011 to March 2021 were retrospectively collected. Patient demographics, indication for testing, genetic information, adverse events and positivity rates were compared by test protocol used. Slow protocol was defined as total dose of $1 \mathrm{mg} / \mathrm{kg}$ ajmaline capped at $100 \mathrm{mg}$, given at rate of $10 \mathrm{mg} / \mathrm{min}$. Rapid protocol was defined as $1 \mathrm{mg} / \mathrm{kg}$ ajmaline capped at $100 \mathrm{mg}$ given in 10 divided doses over 5 minutes.

Results A total of 414 ajmaline challenges were included (251 (61\%) slow vs. 163 (39\%) rapid protocol) [Mean age $41 \pm$ $16 y r s ; 50 \%$ male]. Indications for conducting the test were a) family history of $\mathrm{BrS} 182$ (44\%), b) family history of SADS/ SUD 138 (33\%), c) OOHCA 26 (6\%), d) abnormal ECG 47 (11\%) and e) syncope 21 (5\%). There was no difference in positivity rate between the two protocols (slow (23\%) vs. rapid protocol (17\%), $\mathrm{p}=0.13)$ [table 1]. Comparison of patients by provocation result regardless of the protocol used showed a predominance of (males, 51\% in both groups, $\mathrm{p}=0.96$ ) and (similar mean age of patients, $\mathrm{p}=0.91$ ). Positive patients were more likely to have (a family history of $\mathrm{BrS}$, $\mathrm{p}=0.006$ ) or (an SCN5A genetic variant, $\mathrm{p}<0.05$ ). Patients whose indication was (a family history of SADS/SUD, $\mathrm{p}<0.05$ ) or (abnormal ECG, $\mathrm{p}<0.05$ ) were more likely to yield a negative ajmaline test [table 2]. A single patient experienced ventricular ectopy with the slow protocol. While there were no dysrhythmias with the rapid protocol, two patients experienced QRS broadening necessitating early termination of the protocol but this was not statistically significant. Two patients developed jaundice post provocation with slow protocol, both of which resolved spontaneously.

Conclusion The NI ICC service have performed 414 ajmaline test over the last ten years. Patients with a family history of $\mathrm{BrS}$ are more likely to have a positive provocation challenge,

Abstract 12 Table 1 Demographics of patients by ajmaline challenge protocol

\begin{tabular}{|c|c|c|c|}
\hline & $\begin{array}{l}\text { Group A: Slow protocol } \\
(1 \mathrm{mg} / \mathrm{kg} \text { over } 10 \\
\text { minutes) }\end{array}$ & $\begin{array}{l}\text { Group B: Rapid } \\
\text { protocol ( } 1 \mathrm{mg} / \mathrm{kg} \text { over } \\
5 \text { minutes) }\end{array}$ & $\mathrm{p}$-value \\
\hline No of tests, $n$ (\%) & $251(61 \%)$ & $163(39 \%)$ & $\begin{array}{l}\mathrm{p}=0.61 \\
\text { (ns) }\end{array}$ \\
\hline Age (mean $\pm s d$ ) years & $40 \pm 16$ & $43 \pm 15$ & $\begin{array}{l}\mathrm{p}=0.09 \\
\text { (ns) }\end{array}$ \\
\hline Gender (male: female) & $136: 115$ & $75: 88$ & $\begin{array}{l}\mathrm{p}=0.10 \\
\text { (ns) }\end{array}$ \\
\hline \multicolumn{4}{|l|}{ Indications: } \\
\hline a) Family History of & 105 & 77 & $p=0.28$ \\
\hline BrS & 78 & 60 & (ns) \\
\hline b) Family history of & 17 & 9 & $p=0.23$ \\
\hline SADS/SUD & 34 & 13 & (ns) \\
\hline c) History of $\mathrm{OOHCA}$ & 17 & 4 & $p=0.61$ \\
\hline d) ECG abnormality & & & (ns) \\
\hline e) Unexplained syncope & & & $\begin{array}{l}\mathrm{p}=0.08 \\
\text { (ns) } \\
\mathrm{p}=0.05 \\
\text { (trend) }\end{array}$ \\
\hline Positive result, n (\%) & $57(23 \%)$ & 27 (17\%) & $\begin{array}{l}\mathrm{p}=0.13 \\
\text { (ns) }\end{array}$ \\
\hline Ventricular Arrhythmia & 1 (ventricular ectopy) & 0 & \\
\hline $\begin{array}{l}\text { QRS broadening } \\
\text { resulting in shortening } \\
\text { of protocol }\end{array}$ & 0 & 2 & \\
\hline Jaundice & 2 & 0 & \\
\hline
\end{tabular}

*BrS: Brugada syndrome, SADS/SUD: Sudden arrhythmic death syndrome/Sudden unex plained death, OOHCA: Out of hospital cardiac arrest, ns: non-significant, sig: significant.

Abstract 12 Table 2 Comparison of patients by ajmaline challenge result

\begin{tabular}{|c|c|c|c|c|c|c|c|c|}
\hline $\begin{array}{l}\text { Ajmaline challenge } \\
\text { result }\end{array}$ & $\begin{array}{l}\text { Age } \\
\text { (mean) }\end{array}$ & $\begin{array}{l}\text { Gender Male } \\
(\%)\end{array}$ & $\begin{array}{l}\text { a) Family } \mathrm{Hx} \\
\text { BrS }\end{array}$ & $\begin{array}{l}\text { b) Family Hx of SADS/ } \\
\text { SUD }\end{array}$ & $\begin{array}{l}\text { c) Hx of } \\
\text { OOHCA }\end{array}$ & $\begin{array}{l}\text { d) ECG } \\
\text { abnormality }\end{array}$ & $\begin{array}{l}\text { e) Unexplained } \\
\text { syncope }\end{array}$ & $\begin{array}{l}\text { SCN5A variant } \\
\text { positive }\end{array}$ \\
\hline Positive results & 41.2 & $43 / 84(51 \%)$ & $48 / 84(57 \%)$ & $14 / 84(17 \%)$ & $3 / 84(4 \%)$ & $16 / 84(19 \%)$ & $3 / 84(4 \%)$ & $15 / 84(18 \%)$ \\
\hline Negative results & 41.4 & $168 / 330(51 \%)$ & $134 / 330(41 \%)$ & $124 / 330(38 \%)$ & $23 / 330(7 \%)$ & $31 / 330(9 \%)$ & $18 / 330(5 \%)$ & $5 / 330(2 \%)$ \\
\hline $\mathrm{p}$-value & $\begin{array}{l}\mathrm{p}=0.91 \\
\text { (ns) }\end{array}$ & $\mathrm{p}=0.96$ (ns) & $\mathrm{p}=0.006$ (trend) & $p<0.05$ (sig) & $\mathrm{p}=0.25$ (ns) & $\mathrm{p}<0.05$ (sig) & $\mathrm{p}=0.48$ (ns) & $\mathrm{p}<0.05$ (sig) \\
\hline
\end{tabular}

*BrS: Brugada syndrome, SADS/SUD: Sudden arrhythmic death syndrome/Sudden unexplained death, OOHCA: Out of hospital cardiac arrest, Hx: history, ns: non-significant, sig: significant. 